\title{
Sleep quality in subjects suffering from chronic pain
}

\author{
Mohammad Keilani · Richard Crevenna - Thomas Ernst Dorner
}

Received: 10 June 2017 / Accepted: 15 August 2017 / Published online: 7 September 2017 (C) The Author(s) 2017. This article is an open access publication.

\begin{abstract}
Summary
Background Sleeping problems are very common in patients with chronic pain. The aim of the study was to investigate the association between different dimensions of chronic pain and sleep quality in chronic pain patients.

Methods In this cross-sectional interview-based questionnaire study, patients from 3 different pain treatment centers in Vienna aged 18-65 years, with pain lasting 3 months or longer were asked to participate. The association between the short-form McGill pain questionnaire (SF-MPQ) and sleep quality (sleep onset latency, interrupted sleep due to pain, sleep duration and recovering effect of sleep) was assessed.

Results In this study 121 patients (male 32, female 89 , mean age $49 \pm 9$ years) could be analyzed. Of the patients $38.8 \%$ needed more than 30 min for falling asleep, $63.6 \%$ reported sleep fragmentation, $30.6 \%$ slept less than $5 \mathrm{~h}$ and $60.3 \%$ reported no recovering effect of sleep. The strongest associations between pain characteristics and sleep quality were found for pain intensity and affective pain aspects. Logistic regression analyses revealed that one point more in the total score of SF-MPQ increased the odds of needing more than $30 \mathrm{~min}$ for falling asleep, waking up more than 3 times due to pain, sleeping less than $5 \mathrm{~h}$, and perceiving the sleep as non-recovering, by $6 \%$. Adjusting for physical and psychological quality of life
\end{abstract}

\footnotetext{
M. Keilani $(\bowtie) \cdot$ R. Crevenna

Department of Physical Medicine and Rehabilitation,

Medical University of Vienna, Waehringer Guertel

18-20, 1090 Vienna, Austria

mohammad.keilani@meduniwien.ac.at

\section{T. E. Dorner}

Department for Social and Preventive Medicine, Centre for Public Health, Medical University of Vienna,

Kinderspitalgasse 15/I, 1090 Vienna, Austria
}

lowered the odds ratios and the association was no longer significant.

Conclusion The results underline the importance of paying attention to sleep quality in patients with chronic pain. The results also indicate that psychological factors might mediate the association between pain and sleep quality.

Keywords Chronic pain - Sleep problems - Healthrelated quality of life

\section{Introduction}

Chronic pain affects approximately $19 \%$ of adults in Europe [1]. In Austria 25\% of the adult population is affected by chronic pain [2]. These prevalence rates vary by the types of conditions of chronic pain and rates are higher for women and older adults or subjects with lower educational level [3-5]. Sociodemographic factors, such as sex interact with the mechanisms of coping with chronic pain $[2,6,7]$ and therefore play an important role in the consequences of chronic pain. One of the most frequently reported problems for adults living with chronic pain is sleep disturbance $[1,4,8]$. It is notable that approximately two thirds of the general population with chronic pain are less able or unable to sleep because of pain [1]. According to a study carried out in primary care, approximately $40 \%$ s of chronic pain patients reported poor sleep quality, where age, female sex, low income, higher pain intensity and the presence of depression were significantly associated with poorer sleep quality [9]. In a clinical setting, more than half of patients with chronic pain reported insomnia, and sleep disturbance was significantly associated with pain intensity, sensory pain ratings, affective pain ratings, general anxiety, general depression, and health anxiety [10]. 
The association between chronic pain and sleep disorders is bidirectional [11]; on the one hand pain leads to sleep disturbance and on the other hand, patients with persistent insomnia often develop chronic pain [4]. Psychological factors, such as mood and pain-related attention [12], and pre-sleep arousal [13] have been shown to play an important role in the interaction between sleep quality and chronic pain. Common mental disorders, such as depression and anxiety often emerge together with chronic pain $[2,3$, $14,15]$ and with insomnia [16, 17]. When depression and insomnia co-occur in chronic pain patients, they have adverse effects on many pain outcomes [18].

Studies on sleep quality in chronic pain patients are scarce in the Austrian population. The aim of the present analysis was to investigate the association between different dimensions of chronic pain, such as pain intensity, sensory dimension, and affective dimension and different dimensions of sleep quality, such as time before falling asleep, sleep fragmentation, sleep duration, and recovering effects of sleep in subjects suffering from chronic pain. Additionally, it was the aim to evaluate how this association changed by controlling for possible confounders, such as sociodemographic factors, pain characteristics, and physical and psychological quality of life.

\section{Methods}

\section{Subjects}

This analysis is part of a larger study with the primary aim to assess the cost of illness in patients which chronic pain in Austria. Patients from three different hospital-based outpatient clinics were included in the study: the outpatient clinic of the Department of Physical Medicine and Rehabilitation of the Medical University of Vienna, the headache clinic of the Department of Neurology of the Medical University of Vienna and the pain clinic of the Orthopedic Hospital Speising in Vienna. Inclusion criteria were: chronic pain (pain lasting for at least 3 months) at any body site, age between 18 and 65 years, sufficient knowledge of the German language, and currently no cancer and no psychiatric diseases. Exclusion criteria were current cancer treatment or current psychiatric inpatient treatment according to the patients' report.

\section{Procedures}

Patients were fully informed about the study and the possibility to participate by the treating doctor during a visit to the clinics. In the headache clinic, patients were additionally recruited via mail and asked to participate in the study. Recruitment of study participants lasted from December 2012 to February 2014. All subjects signed an informed consent form to participate in the study. The local ethics committee of the Medical University of Vienna approved the study (EK-number 1624/2012).

\section{Outcome measures}

Location of chronic pain was assessed with a twosided homunculus diagram, and subjects were asked to show on this drawing the body site or body sites in which they experienced chronic pain. In total, 14 different body locations could be identified. This approach was also used in publications based on the Austrian Health Interview Survey [2]. Pain characteristics were assessed with the short-form McGill pain questionnaire (SF-MPQ) [19]. This questionnaire consists of 15 pain descriptors which are assessed on a Likert scale from 0 (none) to 3 (severe), a visual analogue scale (VAS) for the current overall pain intensity ranging from 0 (no pain) to 10 (most severe pain imaginable) and a present pain intensity (PPI) scale to indicate overall pain intensity by labeling current pain from 0 (no pain) to 5 (excruciating pain). The first 11 items were summed to indicate the sensory dimension of pain (e.g. throbbing and aching), with a possible score from 0 to 33 . The next four items were summed to indicate the affective dimension of pain (e.g. fearful and sickening), with a possible score from 0 to 12. The final score for the SF-MPQ was calculated by summing the scores for the sensory dimension, the affective dimension, PPI, and VAS. The total score has a possible range from 0 to 60 . For the study, the German version of the SF-MPQ was used [20].

Sleep was assessed with a questionnaire used in a previous study [21]. From this questionnaire, four questions regarding sleep were applied: [1] "how long do you need to fall asleep?", which could be answered by "up to $30 \mathrm{~min}$ ", "up to $1 \mathrm{~h}$ " and "longer than $1 \mathrm{~h}$ " [2]. "How often is your sleep interrupted due to pain?", which could be answered by "not at all”, "1-3 times per night" and "3 times per night and more" [3]. "How long do you sleep in total?", which could be answered by "less than $5 \mathrm{~h}$ ", " $5-7 \mathrm{~h}$ " and " $7 \mathrm{~h}$ and more" [4]. "Do you feel fresh and recovered after waking?", which could be answered by "yes" or "no". Additionally, the use of sedative medication was assessed with the question "do you use prescribed medication for sleep, such as sedatives, antidepressants, anxiolytic drugs or over the counter medication against sleeping problems?", which could be answered by "yes" or "no".

As the covariate, health-related quality of life (HRQOL) was assessed by the use of the short-form 12 health survey (SF-12 questionnaire), and summed scores for the dimensions of physical and psychological quality of life were calculated [22]. Further covariates were sex, age, and level of education in three levels: primary education (compulsory school up to the age of 15 years), secondary education (apprenticeship, professional/commercial school, and high school up to the age of 19 years), and tertiary education (university). 
Table 1 Characteristics of the 121 participants (male 32, female 89 , mean age $49 \pm 9$ years) with chronic pain

\begin{tabular}{|c|c|c|}
\hline & Mean or $N$ & SD or $\%$ \\
\hline \multicolumn{3}{|l|}{ Level of education } \\
\hline Primary & 21 & 17.4 \\
\hline Secondary & 74 & 61.2 \\
\hline Tertiary & 26 & 21.5 \\
\hline SF-MPQ (sensory dimension) & 11.2 & 6.0 \\
\hline SF-MPQ (affective dimension) & 4.5 & 2.9 \\
\hline SF-MPQ (PPI score) & 3.3 & 0.8 \\
\hline SF-MPQ (VAS) & 4.0 & 2.6 \\
\hline SF-MPQ (total score) & 22.9 & 9.4 \\
\hline Duration of chronic pain (years) & 15.5 & 14.5 \\
\hline Number of painful body sites & 4.1 & 2.8 \\
\hline SF-12 (physical sum score) & 35.4 & 10.6 \\
\hline SF-12 (psychological sum score) & 45.1 & 12.2 \\
\hline \multicolumn{3}{|l|}{ Falling asleep } \\
\hline Up to $30 \mathrm{~min}$ & 74 & 61.2 \\
\hline Up to $60 \mathrm{~min}$ & 24 & 19.8 \\
\hline Longer than $60 \mathrm{~min}$ & 23 & 19.0 \\
\hline \multicolumn{3}{|l|}{ Sleep fragmentation } \\
\hline None & 44 & 36.4 \\
\hline $1-3$ times per night & 57 & 47.1 \\
\hline More than 3 times & 20 & 16.5 \\
\hline \multicolumn{3}{|l|}{ Sleep duration } \\
\hline More than $7 \mathrm{~h}$ & 18 & 14.9 \\
\hline $5-7 \mathrm{~h}$ & 66 & 54.5 \\
\hline Less than $5 \mathrm{~h}$ & 37 & 30.6 \\
\hline \multicolumn{3}{|l|}{ Recovering effect of sleep } \\
\hline Yes & 48 & 39.7 \\
\hline No & 73 & 60.3 \\
\hline
\end{tabular}

Statistical analyses were calculated with IBM SPSS Statistics V21.0. Descriptive statistics were applied to describe the sample characteristics. For this, either mean and standard deviation (SD), where appropriate or numbers $(N)$ and percentages (\%) are indicated. To describe the association between pain characteristics and sleep parameters, analyses of variance (ANOVA) was applied. Finally, stepwise logistic regression models were calculated with the four dichotomized sleep parameters as the dependent variables and the total score of SF-MPQ as the independent variable. After an initial crude model, in model I adjustment was made for age, sex, and level of education. In model II additional adjustment for duration of chronic pain and the number of painful body sites was made. Finally, in model III, additional adjustments were made for the summed scores for physical and psychological quality of life according to the SF-12. Results are presented as odds ratios (ORs) and 95\% confidence intervals (95\% CI).

\section{Results}

In total 121 patients with chronic pain were included in the study. The age range was from 23 to 65 years, and almost three quarters were women. Most of the subjects had secondary education, but the proportion with university as the highest education (one fifth) was remarkably high (Table 1). The majority of subjects indicated that the pain had already lasted for longer than 10 years. Most subjects indicated more than one body site with chronic pain. The most common body sites were lower back (57.9\% of the patients), neck (51.2\%), legs (50.4\%), shoulders (44.6\%), head (35.5\%), hips $(32.2 \%)$, feet and toes $(28.9 \%)$, arms $(25.6 \%)$, upper back $(24.8 \%)$, hands and fingers $(23.1 \%)$, and face (20.7\%). Mean values for the dimensions of SF-MPQ are listed in Table 1. Approximately one fifth of the subjects indicated that they needed more than I h to fall asleep. The majority reported that they woke up regularly due to pain and one third indicated a sleep duration of less than $5 \mathrm{~h}$. Almost two thirds answered that they perceived their sleep as non-recovering ( Table 1). The question regarding the use of sleep medication was answered by $25.6 \%$ with "yes" and $72.7 \%$ with "no" (1.7\% missing).

According to the results of ANOVA, there was a clear association between the affective dimension of pain, the PPI score, the VAS score, the total SF-MPQ score and the duration until falling asleep. There was also a clear association between the affective dimension, the PPI score, and the total score of pain experience with the probability of waking up due to pain. Furthermore, the sensory dimension, the affective dimension, the PPI score, and the total score were significantly associated with the probability of perceiving sleep as recovering. There was no significant association of any pain measure with sleep duration (Table 2).

The binary logistic regression analyses revealed that one point more in the total score of SF-MPQ increased the odds of needing more than $30 \mathrm{~min}$ for falling asleep, waking up more than three times due to pain, sleeping less than $5 \mathrm{~h}$, and perceiving the pain as non-recovering, by $6 \%$ (crude model in Table 3 ). Adjusting for socio-demographic factors (model I, Table 3), duration of pain, and number of painful body sites (model II, Table 3) did not clearly alter the association between pain and sleep parameters; however, adjusting additionally for physical and psychological quality of life lowered the odds ratio (OR) and the association was no longer significant; therefore, a modifying effect of the quality of life on the association between pain perception and sleep quality can be assumed (model III, Table 3).

\section{Discussion}

The results of the present study showed notable sleep disturbances in the sample of patients suffering from chronic pain. The affective dimension of pain and 
Table 2 Mean values of the different dimensions of the SF-MPQ by different sleep parameters (ANOVA)

\begin{tabular}{|c|c|c|c|c|c|c|c|c|c|c|}
\hline & $\begin{array}{l}\text { Sensory di- } \\
\text { mension }\end{array}$ & $P$-value & $\begin{array}{l}\text { Affective } \\
\text { dimension }\end{array}$ & $P$-value & PPI score & $P$-value & $\begin{array}{l}\text { VAS } \\
\text { score }\end{array}$ & $P$-value & $\begin{array}{l}\text { Total } \\
\text { score }^{*}\end{array}$ & $P$-value \\
\hline Falling asleep & & \multirow[t]{4}{*}{0.087} & & 0.005 & & \multirow[t]{4}{*}{0.041} & & \multirow[t]{4}{*}{0.046} & & \multirow[t]{4}{*}{0.003} \\
\hline Up to $30 \mathrm{~min}$ & 10.4 & & 4.0 & & 2.2 & & 3.6 & & 21.1 & \\
\hline Up to $60 \mathrm{~min}$ & 11.1 & & 4.5 & & 3.3 & & 3.9 & & 22.9 & \\
\hline Longer than $60 \mathrm{~min}$ & 13.2 & & 6.2 & & 3.7 & & 5.1 & & 28.6 & \\
\hline Sleep fragmentation & & \multirow[t]{4}{*}{0.055} & & 0.012 & & \multirow[t]{4}{*}{0.044} & & \multirow[t]{4}{*}{0.581} & & \multirow[t]{4}{*}{0.021} \\
\hline None & 9.5 & & 3.5 & & 3.1 & & 3.8 & & 19.8 & \\
\hline $1-3$ times per night & 12.4 & & 5.3 & & 3.5 & & 4.0 & & 25.1 & \\
\hline More than 3 times & 11.5 & & 4.3 & & 3.4 & & 4.5 & & 23.6 & \\
\hline Sleep duration & & \multirow[t]{4}{*}{0.196} & & 0.164 & & \multirow[t]{4}{*}{0.151} & & \multirow[t]{4}{*}{0.476} & & \multirow[t]{4}{*}{0.095} \\
\hline More than $7 \mathrm{~h}$ & 11.0 & & 4.4 & & 3.2 & & 3.6 & & 22.1 & \\
\hline $5-7 \mathrm{~h}$ & 10.6 & & 4.2 & & 3.4 & & 4.0 & & 22.1 & \\
\hline Less than $5 \mathrm{~h}$ & 13.5 & & 5.7 & & 3.7 & & 4.5 & & 27.4 & \\
\hline Recovering sleep & & \multirow[t]{3}{*}{0.026} & & 0.007 & & \multirow[t]{3}{*}{0.015} & & \multirow[t]{3}{*}{0.602} & & \multirow[t]{3}{*}{0.009} \\
\hline Yes & 9.7 & & 3.6 & & 3.1 & & 3.8 & & 20.1 & \\
\hline No & 12.2 & & 5.1 & & 3.5 & & 4.1 & & 24.7 & \\
\hline
\end{tabular}

Table 3 Association between total SF-MPQ-score (independent variable) and the various sleep parameters (dependent variables). Results of stepwise bivariate logistic regression models

\begin{tabular}{|c|c|c|c|c|}
\hline & $\begin{array}{l}\text { Crude } \\
\text { OR (95\% Cl) }\end{array}$ & $\begin{array}{l}\text { Model I } \\
\text { OR (95\% Cl) }\end{array}$ & $\begin{array}{l}\text { Model II } \\
\text { OR (95\% Cl) }\end{array}$ & $\begin{array}{l}\text { Model III } \\
\text { OR (95\% Cl) }\end{array}$ \\
\hline Falling asleep after more than $30 \mathrm{~min}$ & $\begin{array}{l}1.06 \\
(1.01-1.10)\end{array}$ & $\begin{array}{l}1.06 \\
(1.02-1.11)\end{array}$ & $\begin{array}{l}1.06 \\
(1.02-1.12)\end{array}$ & $\begin{array}{l}1.05 \\
(0.99-1.11)\end{array}$ \\
\hline Waking up more than three times due to pain & $\begin{array}{l}1.06 \\
(1.02-1.11)\end{array}$ & $\begin{array}{l}1.07 \\
(1.02-1.12)\end{array}$ & $\begin{array}{l}1.08 \\
(1.02-1.13)\end{array}$ & $\begin{array}{l}1.06 \\
(1.00-1.13)\end{array}$ \\
\hline Sleep duration $<5 \mathrm{~h}$ & $\begin{array}{l}1.06 \\
(1.00-1.12)\end{array}$ & $\begin{array}{l}1.07 \\
(1.01-1.13)\end{array}$ & $\begin{array}{l}1.07 \\
(1.01-1.14)\end{array}$ & $\begin{array}{l}1.03 \\
(0.96-1.11)\end{array}$ \\
\hline No perceived recovering sleep & $\begin{array}{l}1.06 \\
(1.01-1.11)\end{array}$ & $\begin{array}{l}1.05 \\
(1.00-1.10)\end{array}$ & $\begin{array}{l}1.05 \\
(1.00-1.10)\end{array}$ & $\begin{array}{l}1.01 \\
(0.94-1.06)\end{array}$ \\
\hline \multicolumn{5}{|c|}{$\begin{array}{l}\text { Model I: adjusted for age, sex, and level of education } \\
\text { Model II: as model I and additionally adjusted for duration of chronic pain and number of painful body sites } \\
\text { Model III: as model II and additionally adjusted for the sum scores of physical and psychological quality of life (SF-12) } \\
\text { SF-MPQ short-form McGill pain questionnaire, SF-12 short form-12 health survey, OR odds ratio, Cl confidence interval }\end{array}$} \\
\hline
\end{tabular}

pain intensity were particularly associated with sleep problems. The time needed for falling asleep, frequency of waking up in the night, and experiencing sleep as recovering were sleep dimensions most often influenced by pain, whereas sleep duration was only marginally affected by the perception of pain. Interestingly, the association between sleep quality and pain was not influenced by sociodemographic variables, duration of pain or the number of painful body sites; however, physical and psychological quality of life modified this association, since adjustment for those factors lowered the OR and led to a loss of significance of this association.

In the present study, the majority of the patients with chronic pain were females. This relates to the fact that chronic pain disorders have considerable higher prevalence in females than males [7]; however, adjusting for sex did not affect the association between pain and sleep quality (Table 3), hence the association between pain and sleep quality did not show gender differences. In another study, however, female patients with chronic pain reported poorer sleep quality than males [9]. The majority of the participants in our study reported falling asleep in up to $30 \mathrm{~min}$ (Table 1). This result might indicate that falling asleep is not the major sleep difficulty for the majority of chronic pain patients. Nevertheless, the proportion of patients with chronic pain who relatively quickly fall asleep was lower than the proportion (76\%) in the general Austrian population [23]. Furthermore, three out of four pain assessment dimensions (i.e. affective dimension, PPI and global pain intensity), as well as the total score of the SF-MPQ, showed significant associations with sleep latency (Table 2). These results emphasize a link between sleep onset latency and intensity of chronic pain and pain-related cognition. In comparison, Tang et al. reported in their study on patients with chronic back pain that affective pain ratings and health anxiety were significant predictors of impaired sleep latency [10]. Sleep fragmentation (1-3 times per night) was reported in almost half of our patients (Table 1). In contrast, in the observation 
of the general population only $15 \%$ described difficulties in sleep maintenance [23]. In the present study, more than half the subjects reported sleeping $5-7 \mathrm{~h}$ per day (Table 1). Sleep duration showed no significant associations with the mean values of the different dimensions of the SF-MPQ by the form of the different sleep parameters (Table 2). These results are in accordance with the results of the study conducted by Smith et al. [13], who reported an average sleep duration of $6 \mathrm{~h}$ per day in a sample of patients suffering from chronic pain. Nevertheless, while sleep duration did not seem to be impaired in our study, recovering effects of sleep were reported in only a minority of participants (Table 1), and significant associations between non-recovering sleep with the mean values of the different dimensions of the SF-MPQ by the form of the different sleep parameters were found (e.g. sensory dimension, affective dimension, PPI and total score, Table 2).

In our study, the affective dimension of chronic pain (e.g. experiencing pain as tiring exhausting, sickening, fearful, and cruel punishing) showed the highest impact on sleep quality next to pain intensity. This finding underlines the strong effect of psychological factors on the association between pain and sleep. This fact is in line with previous literature, where common mental disorders, such as depression [13, 24-27] and anxiety [24, 26, 27] were highly associated with sleep disturbances in patients with chronic pain.

Sleep disturbance experienced by patients with chronic pain is receiving growing attention as an important factor in the quality of life. In our study, when controlling for the physical and psychological dimensions of the quality of life, the association between pain parameters and sleep quality was lowered and not significant any more. This means that at a given level of quality of life we found no significant association between pain dimensions and sleep dimensions. This can also be interpreted that physical and psychological quality of life mediates the association between pain and sleep quality. Quality of life seems to have a central role for patients with chronic pain, which is in line with a previous Austrian study [28].

Despite the observational nature of our study, some possible clinical implementations should be discussed. Our results might support the assumption that sleep and pain have a bidirectional and reciprocal relationship; therefore, clinicians who manage patients with chronic pain should focus on interventions that relieve pain, as well as on assessing and treating sleep disturbance. This is, however often only addressed as a secondary concern [29]. In addressing sleep quality in patients with chronic pain, it has to be considered that the effect of various medication groups on sleep in chronic pain patients are inconclusive. While non-steroidal anti-inflammatory drugs are sleep neutral, antidepressants and opioids can have positive as well as negative effects on sleep [30].
Finally, our results underline the importance of psychological factors, such as mood, anxiety, depression, and quality of life in the association between pain and sleep quality. These factors should be routinely addressed in the management of patients with chronic pain in terms of assessment, monitoring and defining treatment goals; therefore, a multidisciplinary approach will often be required in order to obtain more comprehensive improvements for patients in medical, functional, and social contexts.

The present study has some limitations. Firstly, it relies solely on self-reported measures of sleep disturbance; therefore, subjective sleep problems might be overestimated by the patients. Nevertheless, a study by O'Donoghue et al. showed that participants with chronic low back pain demonstrated significantly poorer sleep, irrespective of the kind of sleep evaluation (objective or subjective) [31]. Furthermore, the cross-sectional design did not permit any conclusions regarding the direction of the relationship between pain and sleep. It cannot be determined from the results whether sleep disturbance is only a marker for nociceptive processes or whether insomnia might also contribute to hyperalgesia. Additionally, it has to be mentioned that it was only the secondary aim of the study to evaluate the association of pain and sleep quality. The sample was set for the primary aim, to assess the cost of illness in patients with chronic pain. The size of the sample is also a limitation, yielding a low power for some statistical calculations. Finally, we did not assess the clinical diagnoses of common mental disorders, such as depression, anxiety, or stress-related disorders, only the mental dimension of quality of life, which limits conclusions about the mediation of psychological factors.

\section{Conclusion}

Various sleep problems are significantly associated with pain in patients suffering from chronic pain. Physical and psychological dimensions of quality of life notably influence both pain perception and sleep quality and therefore modify the association between pain perception and sleep quality. Because comorbid sleep problems and pain have been related to higher disability, the need to improve sleep quality among patients with chronic pain, and to reduce pain among patients with insomnia, should be an important part of future research.

Acknowledgements Open access funding provided by Medical University of Vienna. We would like to thank the heads, doctors and staff of the three clinics in which the study took place. Furthermore, we would like to thank K. Viktoria Stein for her help in designing the study. Additionally, we would like to thank students Jasmin Ghozlan, Philipp Köppen, Matthias Krauße, Matthias Macsek, Melanie NarodoslavskyGföller, and Matthias Ranftler for performing the interviews with the patients. We are also grateful to Mark Ackerley, Professional Member of the Society for Editors and Proofreaders, 
for the linguistic review of this paper. Furthermore, we thank Andrew J. Haig, MD, active Emeritus Professor of Physical Medicine and Rehabilitation at the University of Michigan, for his comments on this paper.

Conflict of interest M. Keilani, R. Crevenna, and T.E. Dorner declare that they have no competing interests.

Open Access This article is distributed under the terms of the Creative Commons Attribution 4.0 International License (http://creativecommons.org/licenses/by/4.0/), which permits unrestricted use, distribution, and reproduction in any medium, provided you give appropriate credit to the original author(s) and the source, provide a link to the Creative Commons license, and indicate if changes were made.

\section{References}

1. Breivik H, Collett B, Ventafridda V, Cohen R, Gallacher D. Survey of chronic pain in Europe: prevalence, impact on dailylife, and treatment. Eur J Pain. 2006;10(4):287-333.

2. Dorner TE, Stein KV, Hahne J, Wepner F, Friedrich M, Mittendorfer-Rutz E. How are socio-demographic and psychosocial factors associated with the prevalence and chronicity of severe pain in 14 different body sites? A cross-sectional population-based survey. Wien Klin Wochenschr. 2017; https://doi.org/10.1007/s00508-017-1223-x.

3. Mittendorfer-Rutz E, Dorner TE. Socio-economic factors associated with the one-year prevalence of severe pain and pain-related sickness absence in the Austrian population. Wien Klin Wochenschr. 2017; https://doi.org/10.1007/ s00508-017-1222-y.

4. Bjurstrom MF, Irwin MR. Polysomnographic characteristics in nonmalignant chronic pain populations: A review of controlled studies. Sleep Med Rev. 2016;26:74-86.

5. DornerTE, MuckenhuberJ, StroneggerWJ, RaskyE, Gustorff B, Freidl W. The impact of socio-economic status on pain and the perception of disability due to pain. Eur J Pain. 2011;15(1):103-9.

6. Rovner GS, Sunnerhagen KS, Bjorkdahl A, et al. Chronic pain and sex-differences; women accept and move, while men feel blue. PLOSONE. 2017;12(4):e175737.

7. Sorge RE, Totsch SK. Sex Differences in Pain. J Neurosci Res. 2017;95(6):1271-81.

8. Gustorff B, Dorner T, Likar R, et al. Prevalence of selfreported neuropathic pain and impact on quality of life: a prospective representative survey. Acta Anaesthesiol Scand. 2008;52(1):132-6.

9. Karaman S, Karaman T, Dogru S, et al. Prevalence of sleep disturbance in chronic pain. Eur Rev Med Pharmacol Sci. 2014;18(17):2475-81.

10. Tang NKY, Wright KJ, Salkovskis PM. Prevalence and correlates of clinical insomnia co-occurring with chronic back pain. J Sleep Res. 2007;16(1):85-95.

11. Smith MT, Haythornthwaite JA. How do sleep disturbance and chronic pain inter-relate? Insights from the longitudinal and cognitive-behavioral clinical trials literature. Sleep Med Rev. 2004;8(2):119-32.

12. Harrison L, Wilson S, Heron J, Stannard C, Munafo MR. Exploring the associations shared by mood, pain-related attention and pain outcomes related to sleep disturbance in a chronic pain sample. Psychol Health. 2016;31(5):565-77.

13. Smith MT, Perlis ML, Smith MS, Giles DE, CarmodyTP. Sleep quality and presleep arousal in chronic pain. J Behav Med. 2000;23(1):1-13.
14. Dorner TE, Alexanderson K, Svedberg P, Tinghog P, Ropponen A, Mittendorfer-Rutz E. Synergistic effect between back pain and common mental disorders and the risk of future disability pension: a nationwide study from Sweden. Psychol Med. 2016;46(2):425-36.

15. Dorner TE, Alexanderson K, Svedberg P, Ropponen A, Stein KV, Mittendorfer-RutzE. Sickness absence due to back pain or depressive episode and the risk of all-cause and diagnosis-specific disability pension: A Swedish cohort study of 4,823,069 individuals. Eur J Pain. 2015;19(9):1308-20.

16. Rumble ME, White KH, Benca RM. Sleep Disturbances in Mood Disorders. Psychiatr Clin North Am. 2015;38(4):743-59.

17. BlankM,ZhangJ,LamersF, TaylorAD, HickieIB, Merikangas KR. Health correlates of insomnia symptoms and comorbid mental disorders in a nationally representative sample of US adolescents. Sleep. 2015;38(2):197-204.

18. Wilson KG, Eriksson MY, D’Eon JL, Mikail SF, Emery PC. Major depression and insomnia in chronic pain. Clin J Pain. 2002;18(2):77-83.

19. MelzackR. Theshort-formMcGill Pain Questionnaire. Pain. 1987;30(2):191-7.

20. Tal-Akabi A, Oesch P. Schmerzbeschreibung: Short-FormMc-Gill-Pain-Questionnaire (SF-MPQ). Bern: Hans Huber, Hogrefe; 2007.

21. Rohleder K. Umfrage: Zusammenhang von Schmerz und Schlafqualität: Marburg: Deutsches Grünes Kreuz e. V.; 2008.

22. Maurischat C, Ehlebracht-Konig I, Kuhn A, Bullinger M. Factorial validity and norm data comparison of the Short Form 12 in patients with inflammatory-rheumatic disease. Rheumatol Int. 2006;26(7):614-21.

23. Zeitlhofer J, Seidel S, Klosch G, et al. Sleep habits and sleep complaints in Austria: current self-reported data on sleep behaviour, sleep disturbances and their treatment. Acta Neurol Scand. 2010;122(6):398-403.

24. Pilowsky I, Crettenden I, Townley M. Sleep disturbance in pain clinic patients. Pain. 1985;23(1):27-33.

25. Nicassio PM, Moxham EG, Schuman CE, Gevirtz RN. The contribution of pain, reported sleep quality, and depressive symptoms to fatigue in fibromyalgia. Pain. 2002;100(3):271-9.

26. Roberts MB, Drummond PD. Sleep Problems are Associated With Chronic Pain Over and Above Mutual Associations With Depression and Catastrophizing. Clin J Pain. 2016;32(9):792-9.

27. O'Brien EM, Waxenberg LB, Atchison JW, et al. Negative mood mediates the effect of poor sleep on pain among chronic pain patients. Clin J Pain. 2010;26(4):310-9.

28. Stein KV, Dorner TE, Ilias W, Rieder A. Schmerzpatienten und ihre Erwartungen an die arztliche Versorgung. Ergebnisse aus dem Osterreichischen Patientenbericht [Chronic pain patients and their expectations towards physician care. Results from the Austrian Patient Report]. Schmerz. 2010;24(5):468-73.

29. Cheatle MD, Foster S, Pinkett A, Lesneski M, Qu D, Dhingra L. Assessing and Managing Sleep Disturbance in Patients with Chronic Pain. Anesthesiol Clin. 2016;34(2):379-93.

30. Bohra MH, Kaushik C, Temple D, Chung SA, Shapiro CM. Weighing the balance: how analgesics used in chronic pain influence sleep? Br JPain. 2014;8(3):107-18.

31. O'Donoghue GM, Fox N, Heneghan C, Hurley DA. Objective and subjective assessment of sleep in chronic low back pain patients compared with healthy age and gender matched controls: a pilot study. BMC Musculoskelet Disord. 2009;10:122. 